\title{
ARTIFICIAL INTELLIGENCE IN LAW ENFORCEMENT, A REVIEW
}

\author{
Suhaib Alzou'bi, Dr. Haitham Alshibly ${ }^{2}$, Dr. Mohammad Al-Ma'aitah ${ }^{3}$ \\ Al-Balqa' Applied University
}

\begin{abstract}
This research is presenting a critical review of existing methodologies and researches that deal with using AI as a tool of mining data in order to smooth and lead evidence in enforcing law. It will review as well the current situation in Jordan as possible as we can access the current available resources, where the method of mining information and using AI or soft evidence are to be addressed. The research concluded the importance of AI as supportive technology in policing, fighting crimes, cybercrimes, as models for enforcing law, but there were no cutoff evidence in using AI advanced methods in mining data in Jordan police and intelligence, simply because it was impossible mission to access the security information of such bodies.
\end{abstract}

\section{KEYWORDS}

Artificial Intelligence, Knowledge, Law Enforcement, Fraud

\section{INTRODUCTION}

Artificial intelligence (AI) was introduced first time as a term by the father of AI, John McCarthy in Dartmouth at 1956 (Popescu, et.al 2010 and McCarthy, et.al 2006). AI considered to be a branch of computer science, stands for methods involved for solving super-complex problems that cannot be solved by direct calculations or mathematics methods that is making the computer taking a 'human-like' approach to problems. (Moran, 2011, and Azuela, et.al 2006). AI can be applied to calculations in differential and integral calculus, theories of electrical circuit, logical mathematics, as well as game playing fields. (McCarthy, et.al 1985). It acts as a key technology in many new applications, such as banking systems, where AI applied to detect attempted credit card fraud, to telephone systems to understand and recognize the speech, to software systems that response to problems and offer appropriate advice. (Waltz, 1996).

In Game playing AI used to enhance interaction with computer by employing techniques of machine learning with a good dynamics that increase attractive and enjoyable game playing involvement (Galway, et.al 2008). AI efficiently applied in the Health Care field, where healthcare information and knowledge are jointed with tools and capabilities of information technology (Collins, et.al 2012). AI will assist the healthcare specialists to have recommendations, by accessing some resources that supports and will improve the process of making decision (Collins, et.al 2012).

AI used in stock trading areas as stated by Tan et.al (2008) and it is resulting in multiplication returns and increasing the probability of winning trades (Tan, et.al 2008). In computer networking fields AI

DOI : 10.5121/ijait.2014.4401 
solved numbers of network issues such as bad quality of services, selecting best rout problem, allocation of resources, controlling call fees, losing packets of data problems (Ahmad, et.al 2012 and McCarthy, et.al 2006). On his article, Suchánek (2010), showed AI is a competitive advantage value which supports and leads right decision; because accurate information in right time are the prerequisite condition of making good quality decision. (Suchánek, 2010).

Following the same approach, AI used in business dimensions, and involved greatly in law enforcement (McCaney2010); where it can act as a predictive analysis that is effectively involved to anticipate and prevent crime (McCaney2010). PMSEIC (2000), prepared a technical paper that reveal how effect Artificial intelligence used to combat inappropriate behaviour, non-compliance and fraud (PMSEIC, 2000). Redmond and Baveja (2000) and Redmond and Baveja (2002) in their published articles showed how important the role of artificial intelligence software in helping police department to develop and improve a strategic viewpoint toward decision-making.

In Jordan, it was very hard mission to mine information regarding applying AI in police applications due to their strict code of security, accordingly this research paper will as much as possible review the current status in Jordan with regard to using AI as a sort of supportive tool for making decisions, conducting meetings and direct questions were introduced to decision makers.

This research paper is aiming to (i) Reviewing other works and papers that focus of using the new digital technology in one of crucial aspects of life. (ii) Introducing success tools of developed countries in this field. (iii) Summarize Jordanian current situation based on personal communications and visits. This paper was not dedicated to illustrate the details of mathematical models and simulation, but will review the importance of their use in Law enforcement and will introduce some applicable systems throughout the world.

The methodology followed in this research will be as following: (1) Conducting a critical review, where others' works, ideas, and information will be summarized and evaluated through: (i) Scanning the literatures efficiently in order to become well-informed on the subject. (ii) Reviewing the information in the texts and presenting an evaluation of it. (2) Review the current status in Jordan with regard to using AI as a sort of supportive tool for making decisions. (3) Conducting meetings and direct questions were introduced to decision makers.

\section{LITERATURE REVIEW}

\subsection{Historical Perspective}

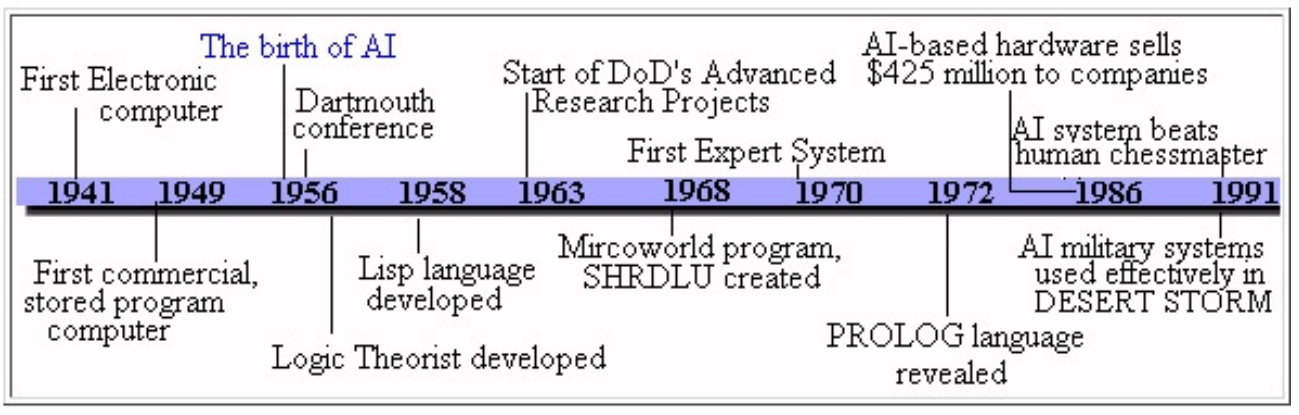

Fig (1) Timeline of major AI events, (Oracle, 1997) 
Figure (1) summarizes the main benchmarks through over the years. Smith, and colleagues (2006) in their review, introduce the history of AI from theory to application, reviewing as well the major themes and advances (Smith, et.al 2006). Schmidhuber (2007) introduce the history

And revolution background of AI and outlook from the arising until 2006 illustrated what should be expected in the next twenty five years. (Schmidhuber, 2007). For the purpose of this paper, a brief will be introduced using the available sources in addition of the reviews conducted by Smith et.al (2006), and Schmidhuber, (2007) to track the historical arise. AI started at beginning of forties until the benchmark development in 1950: Turing's "Computing Machinery and Intelligence“. On 1956, was the year of AI when it had gotten birth, at Dartmouth meeting conference, where John McCarthy first pioneer who adopted the name of Artificial Intelligence (Popescu, et.al 2010 and McCarthy, et.al 2006). In 1950s, Initial promise by early AI programs, including Samuel's checkers program, Newell \& Simon's Logic Theorist, while in the period of 1955-1965 great enthusiasm was witnessed by Newell and Simon: GPS, general problem solver Gelertner: Geometry Theorem Prover and McCarthy: invention of LISP. (Popescu , et.al 2010, Schmidhuber, 2007, McCarthy, et.al 2006, Smith, et.al 2006, Oracle, 1997, Waltz, 1996 and McCarthy et.al 1985). Half of sixties, until 1973, the realization dawns where many AI problems were intractable, the limitations of existing neural network methods were identified and neural network research had been disappears. The main milestones at the end of sixties until the middle of eighties were: adding domain knowledge, development of knowledge-based systems and success of rule-based expert systems, e.g., DENDRAL, MYCIN. Rising of machine learning started at 1986 with major advances in machine learning algorithms and applications. Neural networks return to popularity at the same year (Buscema and Tastle, 2013). In 1990, role of uncertainty was emerging and in addition to Bayesian networks as a knowledge representation framework. Middle of nineties AI classified as science, where the integration of learning, reasoning, knowledge was represented in addition to AI methods used in vision, language, data mining, etc. (Popescu, et.al 2010, Schmidhuber, 2007, McCarthy, et.al 2006, Smith, et.al 2006, Oracle, 1997, Waltz, 1996 and McCarthy et.al 1985). COPLINK is created in 1998 at the Artificial Intelligence Laboratory at University of Arizona at Tuscon, as a revolution in artificial intelligent technology that is depending on pooling the available various information sources that can be brought to improve police officers information (Oatley, et. al 2006).

Among these historical events, success stories were documented such as AI program proved a mathematical conjecture (Robbins conjecture) that was unsolved for decades, another success story for applying AI, and was sort of tragedy to our nation that was during the $1991 \mathrm{Gulf}$ War, where US forces deployed an AI logistics planning and scheduling program (DART Program) that involved up to 50,000 vehicles, cargo, and people. And face recognition software available in consumer cameras on 2006, which later will be used in crime investigations. (Wand, and Milner, 2009).

As with time, the level of knowledge management play an effective role in law enforcement, among moving from the stage of using office applications in to applying artificial intelligence in the stage of using officer to application (Gottschalk, 2008, Gottschalk, 2007).

In 2004, a wide range of intelligence methods were available to support law enforcement; for example in (i) Crime analysis, the following are emerged: crime pattern analysis, geographic analysis, (ii) in investigative analysis such as network analysis, telephone record analysis, and bank record analysis. (iii) And in Strategic analysis: the threat assessments, target profiles, and strategic targeting. (Gonzales, et. al 2005). 


\subsection{Models of Forming an Opinion}

Police, courts, and corrections are operating in an interconnected to form the complex unit of Law criminal justice systems. (Alimadad, et.al 2008). This means that decisions such as legislative, as stated by Alimadad and colleagues (2008) shifts towards harsher sentences for serious criminals, often produce unintended consequences when dealt far a part of the total system, and will change in unanticipated ways (Alimadad, et.al 2008). Because of the fact that the law enforcement agencies in its complex systems must be well functioning and equipped to fight crime and give precise and correct anticepation, there is an urgent need for knowledge experts who are able to discover previously unknown and interesting facts about the data and be able to artificially analyze the crimes as well the ability to simulate characteristics of crime. (Alimadad, et.al 2008 and Gottschalk, 2007).

Application of mathematics in modeling, queuing theory and simulation that depend solely on replications and relationships that can help agencies of enforcing law to emulate and predict the behavior of the justice system more effectively. (Townsley and Johnson 2008).

Modeling and simulation is a mathematical based tool that act effectively and efficiently for law enforcement to analyze the criminal justice system behaviors because they make it possible to handle the uncertainty and variability inherent to complex system interactions with minimum resource expenditure (Alimadad, et.al 2008).

Three different software approaches to modeling and simulating criminal justice systems are used; those are process modeling, discrete event simulation, and system dynamics. (Alimadad, et.al 2008, Hegselmann and Krause 2002).

The main constrains that affect establishing the software modelings are as stated by Zuev and Fedyanin (2012): (1) Computational complexity. (2) Numerous external factors may influence agents. (3) Acquiring reliable initial information for modeling. (4) For sufficiently large periods, the relations among agents may vary. (Zuev and Fedyanin, 2012).

Among software models, a number of progressive law enforcement agencies around the world are starting to use geographic information systems (GIS) with combining many technologies and tools of artificial systems such as dashboards and scorecards, and predictive analytics, data mining, and enterprise search. (Gottschalk, 2008, and Grover, et. al 2007).. CXS as it depends on mathematical modeling to generate a list of cities that are best candidates to cooperate and share experiences. By providing a list of relevant similar communities from whom past experience and learnings can be shared, this tool enables proactive decision-making in police departments. (Redmond and Baveja 2000).

Another good model involving gathering, sharing, analysis and filtering knowledge is the National Intelligence Model (NIM) in the UK. It is a structured approach to improve intelligenceled police. (Bell, et. al 2010 and Gottschalk, 2008). NIM consists of nine individual elements as follows; (1) Crime Pattern (number/relations). (2) Criminal surveys. (3) Demographic/ Social Trend Analysis. (4) Profiling of how criminal operations work. (5) Network analysis (who forms criminal networks). (6) Risk analysis assesses the scale of risks. (7) Target profile analysis. (8) Operational Intelligence assessment maintains (dealt with operation on the previously agreed objectives). (9) Results analysis evaluates the effectiveness of law enforcement activities. (Gottschalk, 2008). 
Knowledge Discovery in Databases KDD, according to his article, Grover, et. al (2007) should be used on all crime types together with offender data in order to predict crime and criminality within a small geographical area of a police force (Grover, et. al 2007). KDD is defined as a field of data mining that uses computer science and engineering to extract knowledge from a very complex and huge amount of data (Grover, et. al 2007, and Gertosio and Dussauchoy 2004). KDD technique begins with analyzing of data stored in different databases or data warehouses and ends with generating new knowledge (Gertosio. and Dussauchoy 2004). KDD technique grouped into four categories: Classification and assembling of data, clustering similarities, time series analysis of values or actions and the fourth category is the association where an identification of a relationship between the attributes is established (Oatley, et. al 2006, and Gertosio. and Dussauchoy 2004)

\subsection{Computer Assistance for Organizational Aspects}

Computers can assist with analysis by compiling large amounts of data into an easily accessible format, for information to be useful, it must be analyzed by a trained intelligence professional or intelligent tool to provide law enforcement executives with facts and alternatives that can inform critical decisions (Gonzales, et. al 2005), this is approved with Oatley, et. al (2006) who concluded in his article that computer science technologies which can support criminal investigations are wide ranging and include geographical information systems displays, clustering and link analysis algorithms and the more complex use of data mining technology for profiling crimes or offenders and matching and predicting crimes. (Oatley, et. al 2006). The risk factors that may be encountered are concluded in directed action, data may be compromised by several risks of lost or amended representing a significant investment through Computer viruses, malware, accidental deletion and hardware failures (Reed, 2011).

Reed (2011), illustrated the forensic computer which defined as the application of scientific and legally accepted techniques on computer systems and digital media in order to extract preserve and report on information contained on those devices or systems. (Reed, 2011). In additional to recover lost data, computer forensics explains how, why and from where, data has been lost, altered or accessed, additionally (computer forensics and forensics practitioners do this with the ultimate aim of preserving the integrity of the evidence so that it may be used in potential administrative, civil or criminal legal action) (Reed, 2011). Its life cycle consists of four stages: identification, collection, analysis, and reporting, and it would be used in police compaince and work continuity serving as Reed (2011) stated a vital role in any organizations incident response planning because of its ability to capture and evaluate quickly data.

\subsection{Link Analysis and Data Mining for Criminal Investigation}

Timely information access and knowledge support is critical for law enforcement. (Gottschalk, 2008 and Oatley, et. al 2004). A link between knowledge in policing includes criminology, psychology, sociology, and law from one direction and technology that help information retrieval must act synergistic in enforcement law in addition to the involvement of management techniques and strategy. (Gottschalk 2008, ).

Technology will depend on exact matches between the search criteria and the fields searched that's obvious clear in most applications with data stored in relational databases either the user or some intermediate software converts the search criteria into appropriate formal statements in the structured query language (SQL), which then return records or documents that exactly match the criteria specified. (Buscema and Tastle, 2013 and Gottschalk 2008). 
In enforcement of law, systems should cover all four stages in the knowledge management technology stage model: officer-to-tools systems, officer-to-officer systems, officer-toinformation systems and officer-to-application systems.

Forensic Led Intelligence System FLINT, a good example for a tool and approach that can be used to join and reveal relations between different data about tangible evidences (shoe-prints, DNA, finger-prints) and intangible behavior evidences (Oatey, et.al 2006, Zeleznikow, et. al 2005 and Oatley et. al 2004). FLINT detects and analyses links, relations, between evidences that cannot be managed in separate form (Fig 4). (Oatey, et.al 2006, and Oatley et. al 2004). It deals with variety and mass amount of data to extract knowledge that is used to enforce law, the main characteristic of FLNT is its ability to (i) deal with different types of data from different resources, (ii) identify correlations between crimes and people that are hidden and ambiguous. (Oatey, et.al 2006, Zeleznikow, et. al 2005, and Oatley et. al 2004)

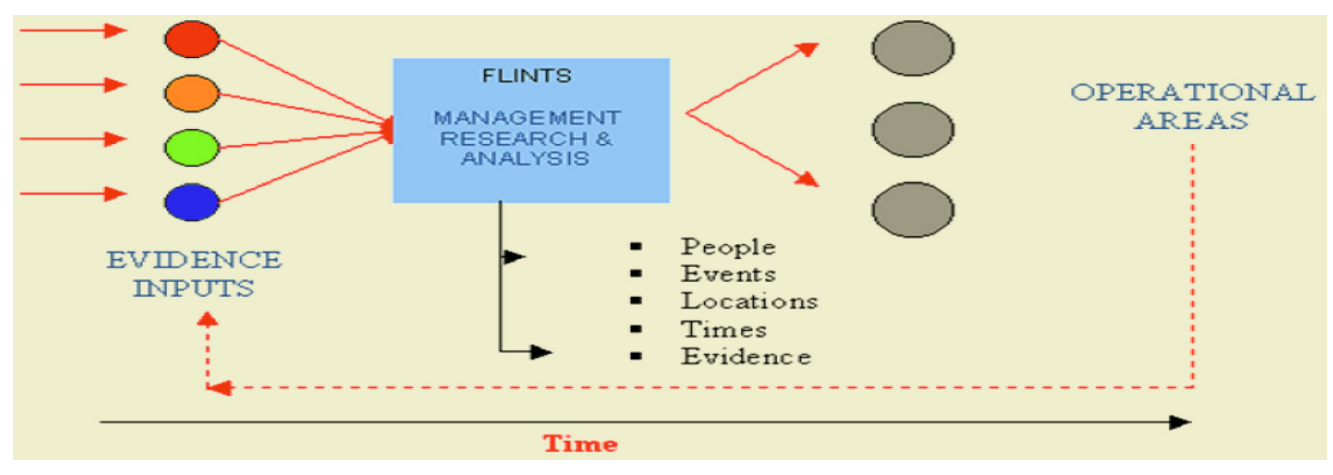

Figure 2 Overview of FLINTS system (Zeleznikow, et. al 2005)

\section{3 .AI and LAW ENFORCEMENT IN JORDAN}

As stated in the national strategy of ICT, Jordan has traditionally been a regional leader in developing, adopting and utilizing information and communication technology (ICT) (Jordan NICT Strategy). Jordan National Information and Communications Technology Strategy (20132017) is recently drafted, mentioning its purpose to be providing Jordan with a defined strategy for addressing areas of specific weakness and opportunity for the purpose of improving the role of ICT in Jordan's economic development and job creation. (Jordan NICT Strategy). Interviewed were accomplished to Intelligence body, directorate of Public Security and directorate of Forensic science to track evidence and methodologies that can be used in their investigations and prevention crimes through involving AI. No one has the authority to declare any information regarding using AI in enforcing law due to high level of security code. Resources of articles which are available in hand revealed the effective application of ICT, computer crimes, cyber crimes, and so on. Jordan did not use information and communication Technologies (ICT) such as electronic payment; (Al-Ma'aitah, 2013). According to his article Al-Ma'aitah (2013), suggested five reasons for not using of e-payment; although the Jordan Information Systems and Cyber Crime Law is issued and enforced; these are: (1) the use of such ICT threats the security and privacy of information of users. (2) The issuance of legislative law was not enough to convince citizens to accept the use of electronic payment. (3) The law in its current content and application still unable to address all forms of threat that users of information and communication technologies face. (4) Some banks and companies in Jordan and particularly in the private sector 
point out that recently privacy became very common. (5) Finally, security and privacy are considered two critical elements in dealing with electronic transactions in general and each other up (Al-Ma'aitah 2013). One of a very important concluded point was a recommendation to prepare judges to be specialists in both fields: law and computer. Method of enforcing such law was not illustrated. Through the searching and mining information and many of personal interviews, and in spite of refusing to fill out the prepared questionnaire from officials, the following were concluded, it is clear that there is application of information management while enforcing law, statistical analysis and geographical information system GIS played the major role in the judging, in addition to perfect traceable filing of crime facts and criminal profiles that depend on the repeatability (personal interviews). Nothing was available to judge any kind of AI tools that may be used, or if there is any method to evaluate the current useable techniques.

\section{CONCLUSION \& RECOMMENDATIONS}

Current prediction techniques have had limited to be understood or revealed due to high strict code of security in our Security Directorates and Bodies. In our view, and due to constrains that limited our mining search to only personal communication with no official covering letters or any written data because there was a full disagree on filling our survey and questionnaire, GIS and the statistical analysis that depend on repeatability and potential correlations are used to its operational policing and enforcing law In Jordan. We are not sure if KDD or other related tool is in hand. Computer crimes are recorded in Jordan, but still we need an extra information to understand how judging the law in such cases. This research recommends the following:

It's worthy if Jordan has efficient contribution in AI and Law international conference, so that success stories may give a good view for upcoming future regarding AI.

It's worthy to search in depth the use of AI in enforcing law in Jordan, requiring the requested support of university and related agencies.

Effective evaluation methods must be conducted in timely manner so that the policing and relevant may judge their effectiveness of work.

\section{REFERENCES}

[1] Ahmad, I., Kamruzzaman, J., and Habib, H., and Habibi, D. (2012). Application of artificial intelligence to improve quality of service in computer networks. Neural Comput \& Applic, 21, 8190.

[2] Alimadad, A., Ghaseminejad, A. H., Borwein, P., Christopher, C.,Brant ingham, P., Li, J., Brantingham, P., Pollard, N., Dabbaghian-Abdoly, V., Rutherford, A., Ferguson, R., van der Waall, Alexa and Fowler, E. (2008). Using Varieties of Simulation Modeling for Criminal Justice System Analysis. Ch 19 In Liu, L. \& Eck, J. Artificial Crime Analysis Systems: Using Computer Simulations and Geographic Information Systems. Premier Reference Source. USA.

[3] Al-Ma'aitah, M. A. (2013). Security Concerns in E-payment and the Law in Jordan. IJACSA International Journal of Advanced Computer Science and Applications, 4, 179-183.

[4] Azuela, J. H. S., Ritter, G., Serra J., and Cortés, U. (2006). Special Issue: Advances in Artificial Intelligence. Instituto Politécnico Nacional Centro de Investigación en Computación.

[5] Bell, P., Dean, J. and Gottschalk, P. (2010). Information Management In Law Enforcement: The Case Of Police Intelligence Strategy Implementation. International Journal of Information Management, 30, 343-349.

[6] Buscema, M., and Tastle W. J. (ED). (2013). Intelligent Data Mining in Law Enforcement Analytics; New Neural Networks Applied to Real Problems. Springer Dordrecht Heidelberg New York London. 
[7] Collins, I. M., Breathnach, O., and Felle, P. (2012). Electronic Clinical Decision Support Systems Attitudes and Barriers to Use in the Oncology Setting. Ir J Med Sci, 181, 521-525.

[8] Galway, L., Charles, D., and Black, M. (2008). Machine learning in digital games: a survey. Artif Intell Rev, 29, 123-161.

[9] Gertosio, C. and Dussauchoy, A. (2004). Knowledge delivery from Industrial Databases. Journal of Intelligent Manufacturing, 15, 29-37.

[10] Grover, V., Adderley, R.and Bramer, M. (2007). Review of Current Crime Prediction Techniques. Applications and Innovations in Intelligent Systems, 14, 233-237

[11] Gonzales , A. R., Schofield , R. B., Herraiz , D. S. (2005). Intelligence-Led / Policing: The New Intelligence Architecture. Bureau of Justice Assistance. NCJ 210681.

[12] Gottschalk, P. (2008). Knowledge Management in Policing: Enforcing Law on Criminal Business Enterprises. Hindawi Publishing Corporation.

[13] Gottschalk, P. (2007). Knowledge Management Systems in Law Enforcement: Technologies and Techniques. Indea Group Inc. USA.

[14] Hegselmann, R. and Krause, U. (2002). Opinion Dynamics And Bounded Confidence Models, Analysis, And Simulation. Journal of Artificial Societies and Social Simulation (JASSS), 5, 1-33. Jordan National Information and Communications Technology Strategy (2013-2017).

[15] McCaney, K. (2010). Law enforcement using analytical tools to predict crime. http://gcn.com/articles/2010/12/22/police-predictive-analysis-software.aspx.

[16] McCarthy, J., Abrahams, B. W., Edwards, D. J., Hart, T. P. and Levin, M. I. (1985). LISP 1.5 Programmer's Manual The Computation Center and Research Laboratory of Eleotronics Massachusetts Institute of Technology. 2nd Ed.. The M. I.T. Press Massrchusetts Institute of Toohnology Cambridge, Massrchusetts. ISBN 0262130114.

[17] McCarthy, J., Minsky, M. L., Rochester, N., and Shanno, C. E. (2006). A Proposal for the Dartmouth Summer Research Project on Artificial Intelligence August 31, 1955. AI Magazine , 27, 12-14.

[18] Moran, L. (2011). http://www.dailymail.co.uk/news/article-2053617/Professor-John-McCarthyFather-artificial-intelligence-dies-aged-84.html.

[19] Pierson, R. M. (2012). Can Artificial Intelligence Detect Crime Before It Happens?. http://www.lockergnome.com/news/2012/08/25/can-artificial-intelligence-detect-crime-before-ithappens/.

[20] PMSEIC Prime Minister's Science, Engineering And Innovation Council. (2000). Science, Crime Prevention \& Law Enforcement. Fifth Meeting - 2 June 2000 Agenda Item 5.

[21] Popescu, V. A., Popescu, G., and Popescu, K. R. (2010). The amazing world of the InternetChalenges of the Internet Age. Information Management, 12, 13-23.

[22] Oatley, G., C., Zeleznikow, F. J. and Ewart, B.W. (2004). Matching and Predicting Crimes. In: Macintosh, A., Ellis, R. and Allen, T. (eds.), Applications and Innovations in Intelligent Systems XII. Proceedings of AI2004, The Twentyfourth SGAI International Conference on Knowledge Based Systems and Applications of Artificial Intelligence, Springer: 19-32. ISBN 1-85233-908-X.

[23] Oatley, G., Ewart, B., and Zeleznikow, F. (2006). Decision support systems for police: Lessons from the application of data mining techniques to "soft" forensic evidence. Artificial Intelligence and Law, 14, 35-100.

[24] Oracle ThinkQuest. (1997). The History of Artificial Intelligence. http://library.thinkquest.org/2705/history.html.

[25] Redmond, M. and Baveja, A. (2000). Aiding Strategic Decision-Making Among Police Departments Using An Artificial Intelligence Software Tool:Website.

[26] Redmond, M. and Baveja, A. (2002). Computing, Artificial Intelligence and Information Technology A data-driven software tool for enabling cooperative information sharing among police departments. European Journal of Operational Research, 141, 660-678.

[27] Reed, R. (2011).Computer Forensics for CEO's and Managers. Eller College of Management. The University of Arizona, Website.

[28] Schmidhuber, J. (2007). 2006: Celebrating 75 years of AI- History and Outlook: the Next 25 Years. http://arxiv.org/abs/0708.4311v1v.

[29] Smith, C., McGuire, B., Huang, T., and Yang, G. (2006). The History of Artificial Intelligence. History of Computing CSEP 590A University of Washington. 
International Journal of Advanced Information Technology (IJAIT) Vol. 4, No. 4, August 2014

[30] Suchánek, P.(2010). Business Intelligence As A Support Of E-Commerce Systems In Connection With Decision Making And Cross Border Online Shopping . Journal of Applied Economic Sciences, 5, 94-102.

[31] Tan, A., Quek, C., and Yow, K, C. (2008). Maximizing Winning Trades Using a Novel RSPOP Fuzzy Neural Network Intelligent Stock Trading System. Appl Intell, 29, 116-128.

[32] Townsley, M., and Johnson, S. (2008). The Need for Systematic Replication and Tests of Validity in Simulation. Ch1 In In Liu, L. \& Eck, J. Artificial Crime Analysis Systems: Using Computer Simulations and Geographic Information Systems. Premier Reference Source. USA.

[33] Waltz, D. L. (1996). Artificial Intelligence: Realizing the Ultimate Promises of Computing. NEC Research Institute and the Computing Research Association, http://homes.cs.washington.edu/ lazowska/cra/ai.html.

[34] Wand, I., and Milner, R. (2009). Computing Tomorrow: Future Research Directions in Computer Science. Cambridge University Press

[35] Zeleznikow, J., Oatley, G., and Leary, R. (2005). A Methodology for Constructing Decision Support Systems for Crime Detection. R. Khosla et al. (Eds.): KESLNAI, 3684, 823-829.

[36] Zuev, A. and Fedyanin, D. (2012). Models of Opinion Control for Agents in Social Networks. Problemy Upravleniya, 2, 37-45. 